\title{
DESENVOLVIMENTO DO PROGRAMA DE QUALIDADE E CAPACITAÇÃO DA REDE PRESTADORA
}

\section{DEVELOPMENT OF QUALIFICATION AND CAPACITATION PROGRAM FOR THE PROVIDER NETWORK}

\section{Diego Augusto Lopes Oliveira}

Enfermeiro, Mestre em Enfermagem pelo programa Associado de Pós-Graduação em Enfermagem UPE/UEPB. E-mail: diegoaugusto.enf@gmail.com. Endereço: Avenida Portugal, nº 1290, bloco 1, apto. 502. Bairro Universitário. CEP: 55016-400, Caruaru-PE.

\section{Marília Fernanda Dantas Florêncio}

Coordenadora Operacional. Unimed Caruaru Cooperativa de Trabalho Médico. E-mail: marilia.dantas@unimedcaruaru.com.br

Célia Maria Lopes de Souza

Gerente Operacional. Unimed caruaru Cooperativa de Trabalho Médico. E-mail: celia.lopes@unimedcaruaru.com.br

Jean Charles Santos

Gerente Operacional. Unimed caruaru Cooperativa de Trabalho Médico. E-mail: celia.lopes@unimedcaruaru.com.br 


\title{
RESUMO
}

Estudo com objetivo de relatar a experiência de uma operadora no desenvolvimento do programa de capacitação e qualificação de sua rede prestadora. Utilizou-se metodologia qualitativa para abordar as ações na implementação de atividades pautadas na pesquisa com beneficiários e com os requisitos de qualidade. Desenvolveram-se palestras, workshops, minicursos e visitas de avaliação por facilitadores com formação e experiência nas temáticas. Estas ações oportunizaram maior vinculação dos prestadores, fortalecimento do relacionamento com a rede, crescimento mútuo e satisfação dos clientes.

Palavras-chave: Serviços de saúde. Saúde suplementar. Qualidade da assistência em saúde.

\begin{abstract}
This study aims to describe the experience of a healthcare insurance company on the development of a capacitation and qualification program to its network provider. The methodology employed was qualitative in order to approach the actions applied, which were based on research with the beneficiaries and on the quality requisites. Talks, workshops, minicourses and visits from Quality were developed. These actions made possible to increase the bond between the providers, to strengthen the relationship with the network, mutual growth and clients' satisfaction.
\end{abstract}

Keywords: Healthcare Services. Health System. Quality in healthcare. 


\section{INTRODUÇÃO}

O cuidado em saúde veio, historicamente, evoluindo e sendo aperfeiçoado para uma atenção pautada no fazer "o bem" aos indivíduos, famílias e comunidades ao qual era desenvolvido. Ao longo do tempo o ideal de segurança foi intrinsecamente atrelado à sua implementação, mesmo que empiricamente, garantindo ações baseadas em padrões de qualidade e na prevenção de erros, danos e possíveis sequelas nos grupos nos quais era aplicado (ANVISA, 2013) (MS, 2013).

Para Reis et al. (2013) a evolução tecnológica advinda da globalização garantiu avanços nos serviços de atenção à saúde, porém, como consequência, promoveu o afastamento dos profissionais do paciente, propiciando clima de insegurança e da ocorrência de Eventos Adversos em Saúde (EAS). Esse clima de insegurança despertou a preocupação com o tema segurança do paciente, que de acordo com Rigobello et al. (2012) pode ser definida, sucintamente, como o ato de evitar, prevenir ou melhorar os resultados adversos ou as lesões originadas no processo de atendimento médico-hospitalar.

No Sistema Nacional de Saúde suplementar os serviços de atenção médico-hospitalar são caracterizados como Rede Prestadora, sendo esta indicada por uma Operadora de Planos de Saúde (OPS) para oferecer cuidado aos beneficiários em todos os níveis de atenção à saúde, considerando ações de promoção, prevenção, diagnóstico, tratamento e reabilitação (ANS, 2017).

O cuidado prestado ao cliente na rede prestadora de atenção é complexo, por isso os profissionais precisam dispor de conhecimento técnico-científico, ter competências e habilidades específicas e conhecer as normas da instituição, bem como os equipamentos utilizados e os procedimentos realizados. Na maioria das vezes o cuidado é prestado de forma bem-sucedida, no entanto, por mais preparada e capacitada que uma equipe de trabalho esteja, erros poderão acontecer, pois errar faz parte da natureza humana (FASSINI \& HAHN, 2012). Nesse trajeto de ideias entende-se, de acordo com Ques (2010), que o sistema hospitalar precisa avançar no tocante a conhecer e reconhecer seus erros, além de propor medidas para evitá-los.

Marck \& Cassiani (2005) levantam a importância do profissional de saúde como membro ativo no processo de estabelecimento de um clima de desenvolvimento de ações seguras, baseadas na promoção de um clima de segurança atrelado a realização de práticas baseadas em padrões de qualidade, na notificação de erros e na criação de cultura de melhoria contínua do processo de cuidado. 
Nessa perspectiva, a Agência Nacional de Saúde Suplementar (ANS), no ano de 2011, publicou a Resolução Normativa $n^{\circ} 277$ que institui o Programa Nacional de Acreditação de Operadoras de Planos de Saúde cujo objetivo é aumentar a qualidade da prestação dos serviços por meio de critérios de avaliação que possibilitam a identificação e solução de problemas por parte das operadoras de planos de saúde com mais consistência, segurança e agilidade. Quanto mais eficiente for a operadora, tanto em aspectos de gestão quanto no atendimento e na satisfação dos consumidores, melhor poderá ser percebida a qualidade dos serviços prestados. Ou seja, além de incentivar a busca pela eficiência, a norma busca oferecer informação capaz de dar ao consumidor maior percepção em relação à qualidade de uma operadora de plano de saúde (ANS, 2017). Para desenvolvimento dessa normativa e garantia da acreditação OPS é necessário o desenvolvimento de requisitos previstos em dimensões da qualidade, definidas em 7 contextos: 1 - Programa de melhoria da qualidade; 2 - Dinâmica da qualidade e desempenho da rede prestadora; 3 - Sistemáticas de gerenciamento das ações dos serviços de saúde; 4 Satisfação do beneficiário; 5 - Programa de gerenciamento das doenças e Promoção à saúde; 6 - Estrutura e Operação e 7 - Gestão (ANS, 2011).

Em sua Dimensão 2, a $\mathrm{RN} \mathrm{n}^{\circ} 277$ propõe o desenvolvimento de estratégias para desenvolvimento dos prestadores para entrega da segurança assistencial aos beneficiários durante a utilização dos seus serviços e, nesse sentido, incentiva as OPS a desenvolver a qualificação dos prestadores médicos e serviços de saúde através do desenvolvimento de programas específicos nos seguintes aspectos: atenção ao beneficiário, segurança nas ações assistenciais, segurança dos dados clínicos, educação permanente dos prestadores médicos e serviços para desenvolvimento de boas práticas.

Os serviços de rede prestadora em saúde ligados às OPS, que constituem o sistema de saúde suplementar no país, possuem relação comercial que estabelece o cumprimento de ações assistenciais aos beneficiários como meio da sustentabilidade dos negócios. O desenvolvimento desta relação promove a prestação dos serviços diretos ao usuário de forma prioritária reduzindo assim a incorporação do componente qualidade e segurança do paciente que expõe a população usuária a riscos assistenciais que repercutem na dinâmica dos serviços de saúde e na própria vitalidade da relação comercial existente.

Nesse sentido torna-se essencial o desenvolvimento de ações voltadas para respaldo e apoio à rede prestadora no sentido de potencializar as ações de cuidado pautada em boas práticas e segurança, para que a partir dessa conjuntura haja aumento no grau de qualidade, satisfação e experiências exitosas na atenção aos beneficiários do sistema de saúde suplementar. 
Este estudo teve como objetivo relatar a experiência de uma operadora de plano de saúde no desenvolvimento do programa de capacitação e qualificação em sua rede prestadora.

\section{METODOLOGIA}

Trata-se de um estudo qualitativo, descritivo, do tipo relato de experiência acerca do desenvolvimento do programa de capacitação e qualificação da rede credenciada de uma operadora de plano de saúde no interior de Pernambuco. A atividade foi incorporada ao processo de trabalho das áreas de relacionamento com prestadores e gestão da qualidade em virtude do pleito deste serviço à certificação voltada ao Programa de Acreditação de Operadoras de planos de Saúde - proposto pela ANS através da RN nº 277/2011. Para desenvolvimento das ações foi instituído escopo baseado nos seguintes passos: 1 - planejamento e elaboração das prerrogativas do programa; 2 - Comunicação e divulgação do programa entre os prestadores; 3 - Desenvolvimento de Auditorias da Qualidade; 4 - Avaliação e pontuação dos prestadores; 5 premiação dos prestadores com destaque na participação e avaliações.

Foram incluídos, no desenvolvimento desta proposta de programa, prestadores de serviços voltados à atenção ambulatorial, terapia renal substitutiva, terapia oncológica, clínicas multiprofissionais, clínicas de físioterapia, clínicas de radiologia, clínicas de oftalmologia, unidades de pronto atendimento e hospitais de média e alta complexidade.

Ressalta-se que não houve necessidade de submissão ao Comitê em ética em pesquisa por tratar-se de um relato envolvendo dinâmicas de processo de trabalho de uma operadora de plano de saúde.

\section{RESULTADOS E DISCUSSÃO}

\section{$1^{a}$ Etapa: Elaboração e Planejamento do Programa}

O desenvolvimento do programa teve como objetivo potencializar as ações da rede prestadora e promover, sob apoio da OPS, ações para melhoria da qualidade dos serviços prestados aos beneficiários. O pleito a certificação proposta pela $\mathrm{RN} \mathrm{n}$ 277/2011 tornou-se essencial para definição dos passos a serem seguidos como meio de implementação das ações previstas no planejamento do programa.

No proposto pela $\mathrm{RN} \mathrm{n}^{\circ} 277 / 2011$ os requisitos relacionados a essa dinâmica estão relacionados à Dimensão 2 - Dinâmica da qualidade na rede prestadora, especificamente os 
requisitos 2.5 (A OPS viabiliza a participação em programas de capacitação e educação continuada em saúde, para sua rede prestadora, com o objetivo de melhorar os resultados da atenção à saúde); 2.6 (A OPS possui procedimento documentado de incentivos à acreditação/certificação de sua rede prestadora e mantém registros atualizados periodicamente sobre o grau de qualidade de sua rede) e 2.7 (A auditoria concorrente - própria ou terceirizada - possui procedimentos documentados de operação, no intuito de aferir a qualidade e adequação dos serviços prestados pela rede).

Foi otimizado grupo de trabalho envolvendo as áreas operacional, de relacionamento com prestadores, comunicação e marketing e gestão da qualidade com a finalidade de desenvolver estratégia e formulação de um programa voltado à inserção do componente qualidade e segurança do paciente na rede assistencial prestadora. Inicialmente foram otimizados encontros para definição dos objetivos do programa, levando em consideração principalmente os dados de pesquisa de satisfação relacionados às experiências vivenciadas pelos beneficiários na utilização dos serviços da rede.

A partir dessas prerrogativas foram instrumentadas as etapas de desenvolvimento do programa bem como as necessidades operacionais para sua implementação.

Para seguimento da primeira etapa, os prestadores da rede receberam convite formal, através de comunicação da diretoria presidente da OPS, informando sobre a importância do programa, bem como e-mail com briefing contendo as informações gerais e forma de participação nas ações. Aderiram a participação 30 prestadores das áreas de atenção ambulatorial, terapia renal substitutiva, terapia oncológica, clínicas multiprofissionais, clínicas de fisioterapia, clínicas de radiologia, clínicas de oftalmologia, unidades de pronto atendimento e hospitais de média e alta complexidade.

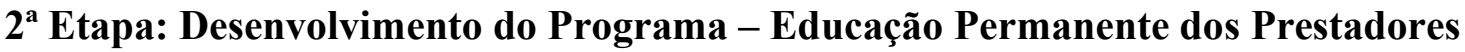

A segunda etapa do programa foi composta por 05 ciclos de atividades de educação permanente voltadas aos pontos críticos referenciados pelos beneficiários na avaliação de satisfação desenvolvida e com foco na melhoria contínua destes serviços. Essas atividades ocorreram de forma mensal, com programação prévia e divulgação entre os participantes, sendo instrumentadas na forma de palestras, oficinas e workshops, obedecendo a adequação a cada temática trabalhada. As atividades foram direcionadas para colaboradores das empresas da rede prestadora (secretarias, atendentes, recepcionistas, profissionais de saúde e gestores). 
A implementação das atividades de educação permanente e capacitação da força de trabalho nos prestadores pode ser entendida como forma de aumentar a capacidade empreendedora destes serviços, dessa forma potencializando seus negócios e fortalecendo sua marca e a atividade produtiva em saúde na região. Esse foi o objetivo da criação de parceria junto ao Serviço Brasileiro de Apoio às Micro e Pequenas Empresas (SEBRAE) como órgão colaborador no sentido de apoiar as ações de melhoria contínua e elucidar a importância do empreendedorismo na área de saúde com foco na qualidade. A parceria foi de grande valia para organização do programa e captação de facilitadores com alta expertise a fim de fomentar eventos com maior atratividade, fundamentação científica e que oferecessem contribuições para melhoria dos serviços.

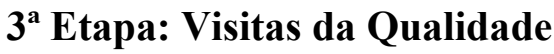

A terceira etapa do programa foi composta por atividades intituladas como "Visitas da Qualidade", estas com objetivo de realizar auditoria concorrente dos serviços a fim de avaliar suas práticas e promover ações de melhoria nos processos com apoio da operadora, fortalecendo o vínculo com os prestadores e melhorando a entrega ao cliente da OPS. As visitas foram organizadas em cronograma definido pela área de gestão da qualidade e com agendamento prévio junto aos serviços e foram orientadas a partir de instrumentos de auditoria elaborados pela área baseado nos padrões reconhecidos nacionalmente para as especificidades dos prestadores. A operacionalização das visitas se deu por profissionais com know-how na área e com formação em auditoria interna da qualidade.

Após desenvolvimento das visitas foram elaborados relatórios de feedback das visitas de qualidade realizadas aos prestadores. Esse documento continha os dados relacionados a operacionalização da visita com destaques aos pontos positivos, não conformidades e oportunidades de melhoria sendo estas embasadas nos dispositivos legais e de boas práticas validadas. O envio dessas informações ao participante teve a intenção de formalizar e garantir maior respaldo à avaliação realizada bem como criar vínculo com a OPS de forma a desenvolver, junto ao prestador, ações de consultoria e orientação para implantação dos requisitos necessários a agregação do componente segurança as suas ações assistenciais.

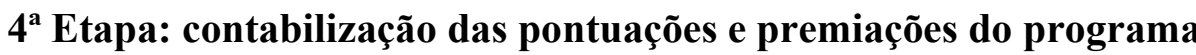


$\mathrm{Na}$ última etapa de desenvolvimento do programa foram contabilizadas as pontuações obtidas na participação dos eventos do programa. Durante toda a realização dos eventos a assiduidade, colaboração e desempenho dos prestadores foi traduzida em pontuações que somadas geraram um coeficiente geral de participação e indicavam o participante a premiação em uma categoria, dentro da sua especificidade, sendo destacados: Categoria Ouro: prestadores com desempenho pontuado acima de 80 pontos; Categoria Prata: entre 41 e 79 pontos e Categoria Bronze: pontuados em até 40 pontos.

$\mathrm{O}$ evento de encerramento do ciclo do programa promoveu atividade educativa e comemorativa das ações desenvolvidas, onde foi divulgado o resultado final do programa com premiação aos participantes que atingiram o selo Categoria Ouro.

Os prestadores referem alta satisfação no desenvolvimento do programa por permitir trabalhar suas potencialidades dentro das necessidades expressas pelo cliente e com apoio do órgão regulador, nesse caso a OPS. Outro aspecto pontuado é a melhora da relação com a OPS através da oferta de parcerias para desenvolvimento do prestador e, em especial, das ações de qualificação com foco na segurança do paciente.

\section{CONSIDERAÇÕES FINAIS}

A proposta de desenvolver um programa de fortalecimento da rede prestadora agrega às atividades da operadora por fornecer subsídios que superam a relação contratual e busca benefício direto aos beneficiários. Esses subsídios vão além da informação científica e se estendem a melhora da relação, da criação de canais de comunicação e troca de informações qualitativas em saúde que contribuem substancialmente para manutenção dos serviços na oferta de experiências cada vez mais positivas ao usuário.

\section{REFERÊNCIAS}

BRASIL. Agência Nacional de Saúde Suplementar. Resolução Normativa no 277 de 2011Institui o programa de acreditação de operadoras de planos privados de assistência à saúde. Disponível em: https://bit.ly/2ml80k3. Acesso em 06 abr. 2018.

BRASIL. Agência Nacional de Saúde Suplementar. Anexo da Resolução Normativa $n^{\circ} 277$. Disponível em: https://bit.ly/2kEJiLb. Acesso em: 06 abr. 2018.

BRASIL. Agência Nacional de Saúde Suplementar. Acreditação de Operadoras. Disponível em: https://bit.ly/2kmmfo9. Acesso em 06 abr. 2018.

BRASIL. Agência Nacional de Saúde Suplementar. Rede Prestadora de serviços de saúde. Disponível em: https://bit.ly/2m086ND. Acesso em 06 abr. 2018. 
BRASIL. Agência Nacional de Vigilância Sanitária. Assistência Segura: Uma reflexão teórica aplicada à prática. Série: Segurança do paciente e qualidade nos serviços de saúde. $1^{\text {a }}$ Edição, Brasília- DF, 2013.

BRASIL. Agência Nacional de Vigilância Sanitária. RDC nº 36/2013 - Institui Ações para segurança do paciente em serviços de saúde e dá outras providências. Disponível em: https://bit.ly/2owS11u. Acesso em 10 abr. 2018.

BRASIL. Ministério da Saúde. Portaria GM no 529/2013 - Institui o Programa Nacional de Segurança do Paciente (PNSP), Brasil, 2013. Disponível em: https://bit.ly/2htwq8y

FASSINI, Patricia; HAHN, Giselda Veronice. Riscos à segurança do paciente em uma unidade de internação hospitalar: Concepções da equipe de enfermagem. Rev. Enferm UFSM. v. 2, n. 2, p. 290-299, maio/ago. 2012. Disponível em: https://bit.ly/2kEVxaA. Acesso em: 10 abr. 2018.

MARCK, Patricia; CASSIANI, Silvia Helena de Bortoli. Teorizando sobre sistemas: Uma tarefa ecológica para as pesquisas na área de segurança do paciente. Rev Latino-am Enfermagem, v. 13, n. 5, p. 750-753, set/out. 2005. Disponível em: https://bit.ly/2kP4UV2. Acesso em: 10 abr. 2018.

QUES, Angel A. M. et al. Fortalezas e ameaças em torno da segurança do paciente segundo a opinião dos profissionais de enfermagem. Rev Latino-am Enfermagem, v. 18, n. 3, p. 42-49, maio/jun. 2010. Disponível em: https://bit.ly/2mlr0Ps. Acesso em: 10 abr. 2018.

REIS, Claudia Tartaglia; MARTINS, Monica; LAGUARDIA, Josué. A segurança do paciente como dimensão da qualidade do cuidado de saúde - um olhar sobre a literatura. Ciência \& Saúde Coletiva, v. 18, n. 7, p. 2029-2036, set/out. 2013. Disponível em: https://bit.ly/2kOlT9Z. Acesso em: 10 abr. 2018.

RIGOBELLO, Mayara C. G. et al. Clima de segurança do paciente: percepção dos profissionais de enfermagem. Acta Paul Enferm, v. 25, n. 5, p. 728-35, 2012. Disponível em: https://bit.ly/2nRVARv. Acesso em: 10 abr. 2018. 